\title{
Heat Treatment Effect on Lath Martensite
}

\author{
Enikő Réka FÁBIÁN, ${ }^{1}$ Áron KÓTAI ${ }^{2}$ \\ ${ }^{1}$ Óbuda University, Donát Bánki Faculty of Mechanical and Safety Engineering, Department of Materials \\ Technology, Budapest, Hungary, fabian.reka@bgk.uni-obuda.hu \\ ${ }^{2}$ Budapest University of Technology and Economics, Department of Materials Science and Engineering, \\ Budapest, Hungary, aron.kotai@gmail.com
}

\begin{abstract}
During our investigation lath martensite was produced in low carbon steels by austenitization at $1200{ }^{\circ} \mathrm{C} / 20 \mathrm{~min}$, and the cooling of samples in ice water. The samples were tempered at a range of temperatures. The tempering effects on microstructure and on mechanical proprieties were investigated. Some samples with lath martensite microstructure were cold rolled and heat treated at different temperatures. Recrystallization was observed after heat treatment at $600-700{ }^{\circ} \mathrm{C}$.
\end{abstract}

Keywords: low carbon steel, lath martensite, heat treatment.

\section{Introduction}

Lath martensite in steel shows a hierarchical microstructure consisting of packets, blocks, subblocks, and laths. The prior austenite grain is divided into packets that consist of blocks. These blocks in a packet have the same habit plane. The packet is further divided into platelike blocks, which consist of laths with a similar crystal orientation. Lath martensite can be formed in low carbon steel.

It was found [1] that the martensite in the low carbon steels is predominantly lath martensite (under $0.3 \% \mathrm{wt} \% \mathrm{C}$ ) and plate martensite appears above $0.6 \mathrm{wt} \% \mathrm{C}[2]$. The morphology and crystallography of lath martensite has been studied by many researchers in recent years [3-5].

\section{Materials and testing}

As the first step in our experiment, the lath martensitic microstructure was created in low carbon unalloyed steel $(\mathrm{C}=0.15 \%, \mathrm{Mn}=1.43 \%$, $\mathrm{Si}$ $=0.29 \%$ ). It has been found in the literature that lath martensite can be formed in low-carbon steels by intensive quenching after austenitization at high temperatures. According to our experi- ments, the higher austenitization temperature supports the more secure formation of the lath martensitic microstructure. The sizes of laths in sub-blocks and blocks are larger and more characteristic after austenitization at $1200^{\circ} \mathrm{C}$, than at lower temperatures (Figure 1-2).

For our experiments, the lath martensitic microstructures were prepared by austenitization of samples at $1200^{\circ} \mathrm{C}$ for 20 minutes and then cooled in ice water.

The properties of lath martensite created in non-alloyed low carbon steel were investigated after heat treatment at different temperatures. For this reason the samples were tempered at $200^{\circ} \mathrm{C}, 300^{\circ} \mathrm{C}, 400^{\circ} \mathrm{C}, 500^{\circ} \mathrm{C}, 600^{\circ} \mathrm{C}$ and $700^{\circ} \mathrm{C}$ for 20 minutes, To study exactly the heat treatment effects, the microstructure of the samples was frozen by water cooling.

Impact tests according to MSZ EN ISO 148-3: 2009 on a Charpy impactor were carried out. The tensile tests according to MSZ EN ISO 6892-1: 2016 by Heckert Tiratest 2300 tensile machine were studied. The crossover velocity was $1.5 \mathrm{~mm} / \mathrm{min}$. The hardness of the samples was measured using a KB Prüftechnik KB 250 BVRZ type universal hardness tester, and Vickers hardness measure- 

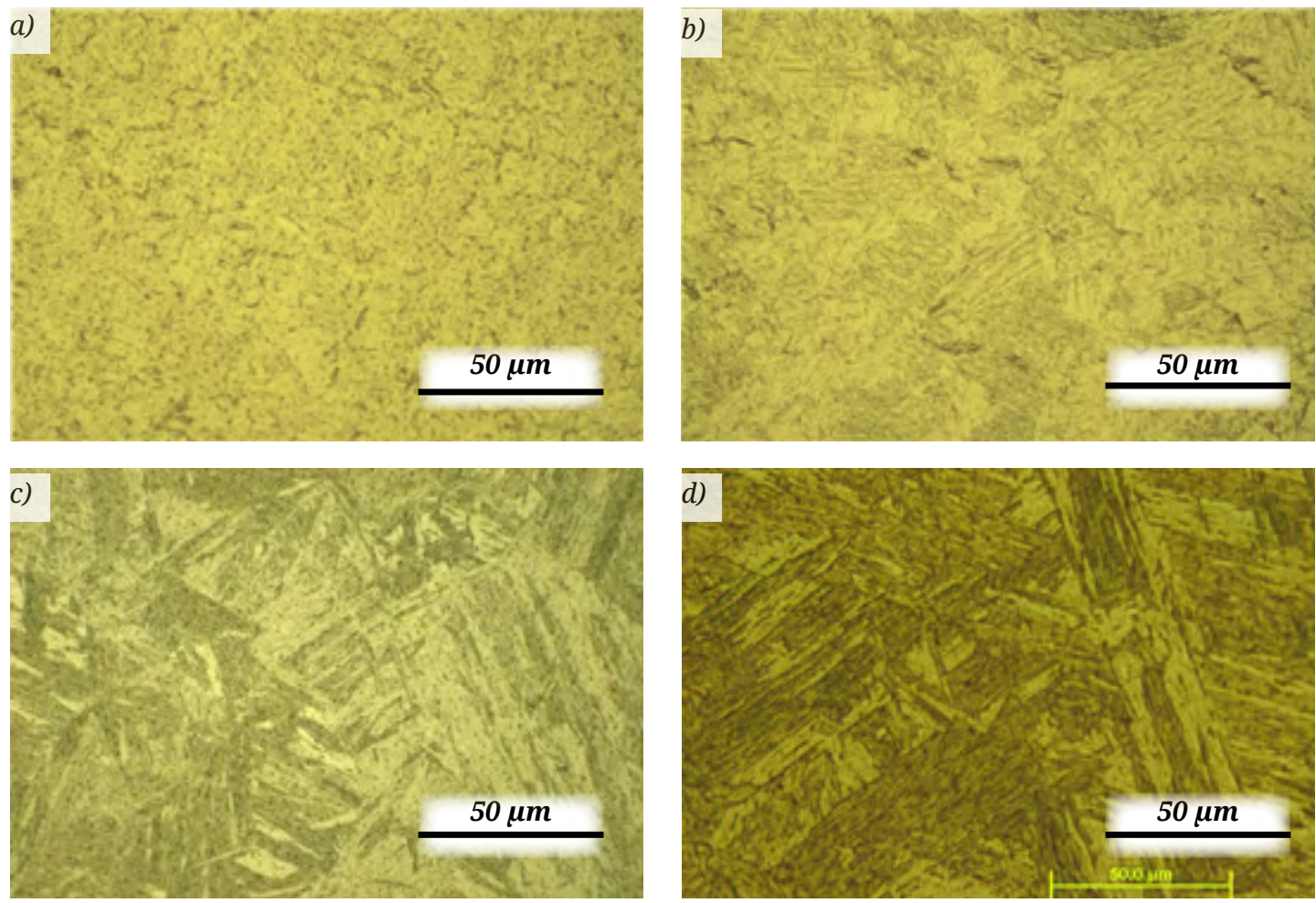

Figure 1. The effects of austenitization tempera-tures on the microstructure a) $T_{\text {aust }}=900{ }^{\circ} \mathrm{C}$; b) $T_{\text {aust }}=1000^{\circ} \mathrm{C}$; c) $\left.T_{\text {aust }}=1100{ }^{\circ} \mathrm{C} \mathrm{d}\right) T_{\text {aust }}=1200{ }^{\circ} \mathrm{C}$

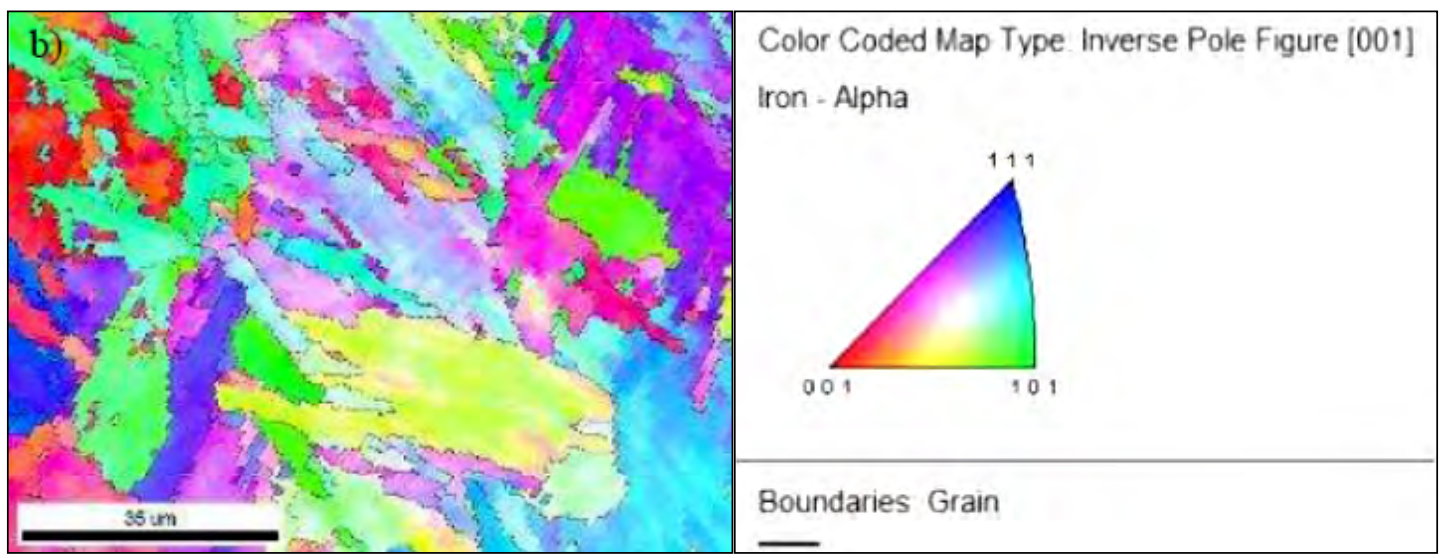

Figure 2. Orientation map of quenched samples after austenitization at $1200{ }^{\circ} \mathrm{C}$.

ment. The microstructures of the samples were studied with an Olympus PMG3 light microscope. Investigation of the orientation of the grains, and the small and large angle grain boundaries were achieved by electron diffraction (EBSD) on a Philips XL 30 electron microscope.

Our examinations were extended to examine the effect of cold deformation and subsequent heat treatments. Therefore, $10 \times 10 \times 55 \mathrm{~mm}$ samples were rolled on a duo cylinder stand, and after each formulation we studied the effect of post-treatment temperatures. The post heat treatment conditions were similar to heat treatments applied to undeformed samples. 


\section{Results}

As can be seen from Charpy's impact tests, the toughness of the lath martensite after tempering between $200-400{ }^{\circ} \mathrm{C}$ is very small, under $50 \mathrm{~J}$. Increasing the tempering temperature increases the toughness. After tempering at $700^{\circ} \mathrm{C}$, the toughness of the material was better than that of the normalized base material (Figure 3 ).

Tensile tests (Figure 4) showed that elongation at rupture of sample quenched (with lath martensitic microstructure) slightly exceeded $10 \%$. Although the elongation at rupture generally increases with the tempering temperature, when the tempering temperature is $400^{\circ} \mathrm{C}$ the value is the lowest (between the all measured values is the minimum). Although the toughness of the samples tempered at $700^{\circ} \mathrm{C} / 20$ minutes was higher than that of the normalized samples, the elongations at ruptures remain lower than the tensile test specimens in normalized states.

The relationship between the tempering temperature and the tensile strength is confirmed by the tests results The quenching achieved tensile strength (800 MPa), the decreasing of the tensile strength is caused by the $500{ }^{\circ} \mathrm{C}$ or higher temperature tempering. The character of lath martensite could be observed in the microstructure after tempering at $700{ }^{\circ} \mathrm{C}$ (Figure 5).

Cold rolling of the LM material indicated that the material hardened during forming (Figure 6) but no cracks occurred even after $86 \%$ deformation (535HV10). Further deformations were limited by the 55HRC hardness of the rolling mill cylinders.

Studies carried out after several deformations and heat treatment at various temperatures show that even after extensive deformation, a considerable amount of heat is needed for the recrystallization of unalloyed low carbon with lath martensitic microstructure. While after $62 \%$ deformation and heat treatment at $500{ }^{\circ} \mathrm{C} / 20 \mathrm{~min}$, by optical microscope we could not observe signs of recrystallization (Figure 7), studying the samples by EBSD method at high resolution, in image-quality maps it was possible to distinguish dislocation-free sub-grain centre and dense dislocation network at the sub-grain boundaries (Figure 8). On the orientation map it resembled an anisotropic appearance of material.

The hardness of the samples which were deformed more than $30 \%$ and heat treated at 600 $700{ }^{\circ} \mathrm{C}$ become less than 200HV10, in these samples - in image-quality maps, a recrystallized equiaxed microstructure can be observed (even if the grain size is different after 20 minutes of heat treatment at $700{ }^{\circ} \mathrm{C}$ ) (Figure 9).

\section{Conclusions}

The lath martensitic microstructure in low carbon unalloyed steel has very good deformability and is very stable even at high temperatures.

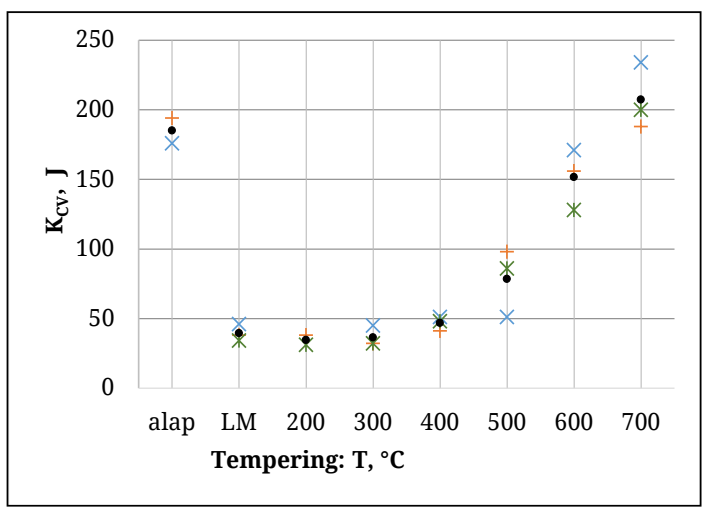

Figure 3. Tempering effect on impact energy $(b m=b a-$ sic normalized structure, $L M=$ lath martensitic structure)

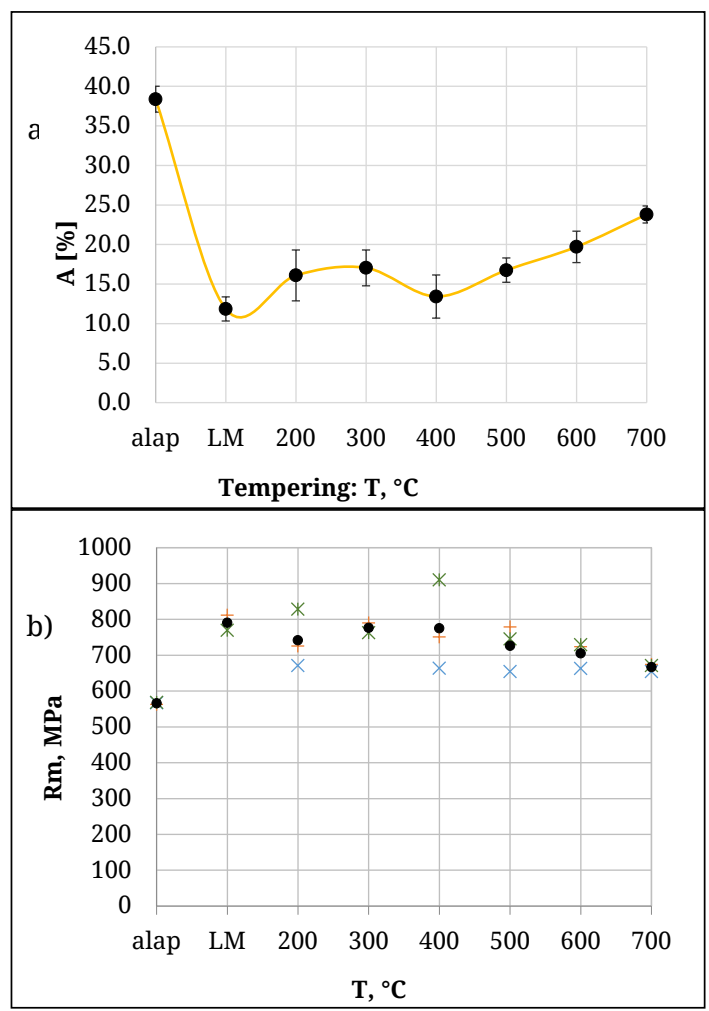

Figure 4. Tempering effects on elongation at rupture (a) and on tensile strength (b) 


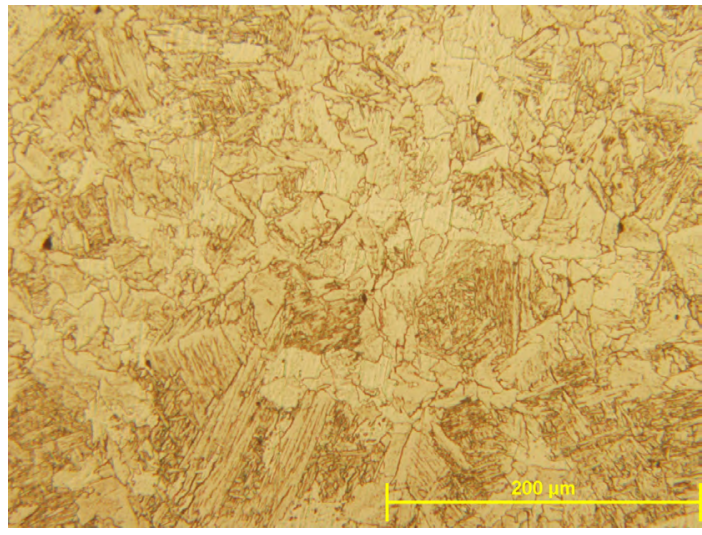

Figure 5. Microstructure of the LM sample tempered at $700{ }^{\circ} \mathrm{C}$

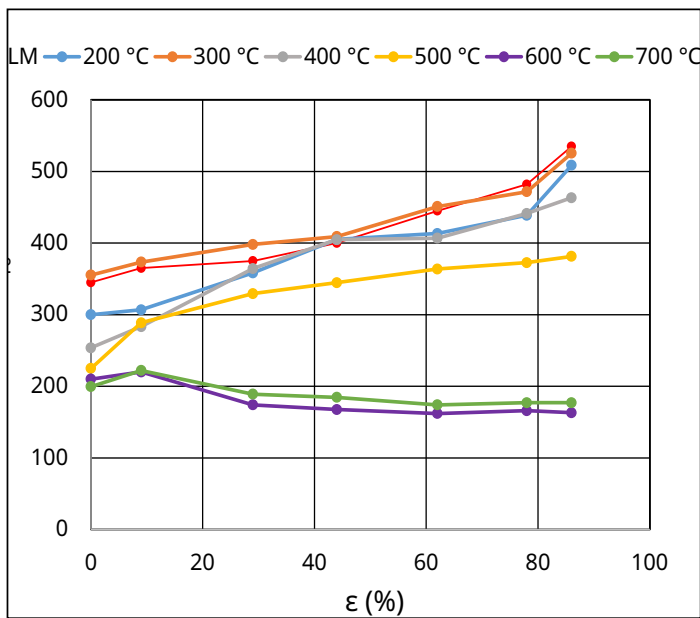

Figure 6. Cold rolling and tempering effects on hardness of samples with lath martensitic microstructure

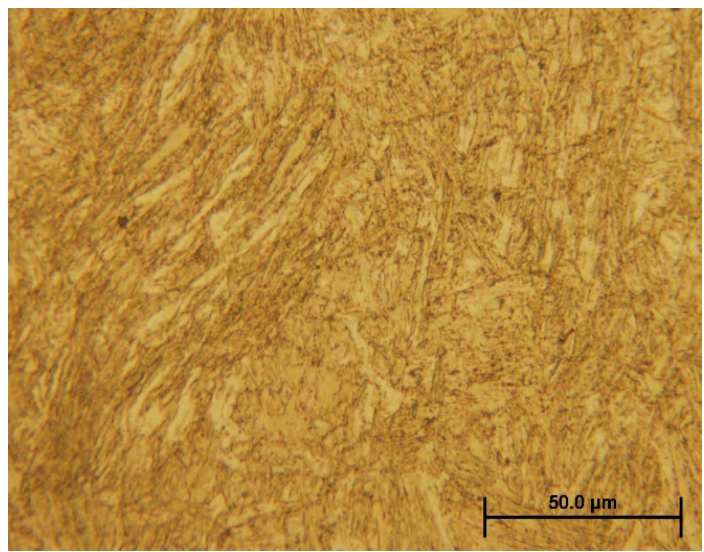

Figure 7. Microstructure of sample deformed $\varepsilon=62 \%$ and tempered at $500{ }^{\circ} \mathrm{C}$
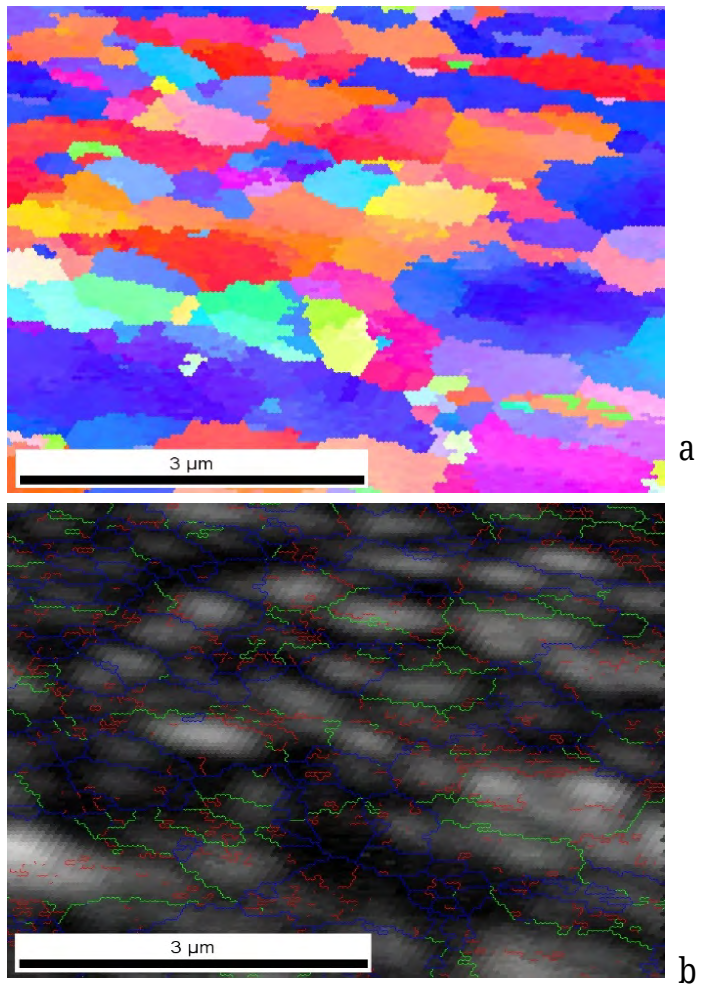

Figure 8. EBSD images, $\varepsilon=44 \%, T=500^{\circ} \mathrm{C}, N=10000 x$. a) Pole figure map $b$ ) Image quality map

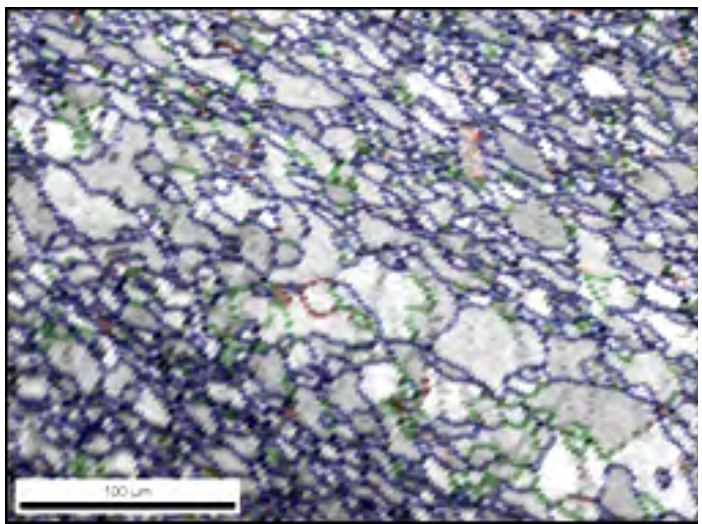

Figure 9. Image quality map at sample, $86 \%$, $T=700{ }^{\circ} \mathrm{C}$

\section{Acknowledgments}

The authors wish to express their thanks for the financial support given by the project EFOP-3.6.1-162016-00010. 


\section{References}

[1] Stormvinter A., Hedström P., Borgenstam A.: Investigation of lath and plate martensite in a carbon steel. Solid State Phenomena, 172-174. (2011) 61-66.

https://doi.org/10.4028/www.scientific.net/SSP.172174.61

[2] Sandvik B. P. J., Wayman C. M.: Crystallography and substructure of lath martensite formed in carbon steels. Metallography, 16/2. (1983) 199-227. https://doi.org/10.1016/0026-0800(83)90005-8
[3] Kelly P. M.: Crystallography of lath martensite in steels. Materials Transactions, JIM (Japan), 33/3. (1992) 235-242.

https://doi.org/10.2320/matertrans1989.33.235

[4] Morito S., Tanaka H., Konishi R., Furuhara T., Maki T.: The morphology and crystallography of lath martensite in $\mathrm{Fe}-\mathrm{C}$ alloys. Acta Materialia, 51/6. (2003) 1789-1799.

https://doi.org/10.1016/S1359-6454(02)00577-3

[5] Morito S., Adachi Y., Ohba T.: Morphology and crystallography of sub-blocks. Materials Transactions, 50/8. (2009) 1919-1923.

https://doi.org/10.2320/matertrans.MRA2008409 